\title{
A 'POSTERIOR RING' IN THE SPERMATOZOA OF SPECIES OF MURIDAE
}

\author{
D. M. WOOLLEY* \\ Department of Genetics, Edinburgh University
}

(Received 17th Fune 1970)

\begin{abstract}
Summary. An examination of surface replicas of spermatozoa from five Muridae species has confirmed the existence of a 'posterior ring' encircling the nucleus. The post-acrosomal surface is subdivided by this ring into two areas, the post-nuclear cap and a smaller more distal region which, in these preparations, has a characteristic topography.
\end{abstract}

Gresson \& Zlotnik (1945) considered that the argentophil post-nuclear cap of the mammalian spermatozoon does not extend posteriorly as far as the insertion of the flagellum but leaves a narrow unstained space along the posterior edge of the nucleus. They also suggested that a separate structure, which they called the 'posterior ring', lies around the posterior border of the nucleus. Hancock \& Trevan (1957) also thought that a separate structure existed behind the post-nuclear cap of the bull spermatozoon. Recently, a definitive ring-like structure has been described in thin sections of rat spermatozoa (Pikó, 1969) apparently coinciding with the posterior limit of the post-nuclear cap. The present communication reports that the 'posterior ring' seen in Piko's electron micrographs and a distinctive surface region behind it are clearly visible in carbon replicas of Muridae spermatozoa.

Spermatozoa were obtained from the cauda epididymidis of freshly killed specimens of Peromyscus polionotus, P. maniculatus, Rattus norvegicus, Mus musculus and Clethrionomys glareolus. They were suspended in $0.85 \%$ saline and fixed by the addition of neutralized formalin to a final concentration of $2 \%$ formaldehyde. The spermatozoa were then centrifuged, resuspended in distilled water, and allowed to dry on a microscope slide. The carbon replicas, made according to the procedure given in detail elsewhere (Woolley, 1970), were shadowed with palladium-gold and examined in a Philips EM 75. Excepting Clethrionomys glareolus, the observations were made on more than one individual from each species.

A 'posterior ring' was clearly visible in the spermatozoa of the five species studied. It is obviously the boundary between two distinctly different surfaces, a finding which supports Piko's view that the ring lies at the posterior limit of the post-nuclear cap. The smaller surface, between the ring and the insertion of the flagellum, will be referred to provisionally as the 'basal surface'; its topography appeared essentially similar in these five species, though the

* A.R.C. Unit of Animal Genetics. 
mouse preparations were consistently the least clear. Compared with the postnuclear cap, this surface has an uneven appearance, being divided up, more or less regularly, into rows of approximately circular features which have much the same diameter (about $900 \AA$ ) in the five species. This same appearance was found in replicas of unfixed cells. In cells subjected to severe sonication, the replicas showed the 'posterior ring' and the features of the 'basal surface' unchanged, but in some of the cells which had lost their acrosomes, the subacrosomal surface of the nucleus also showed reticular patterns similar to, though much less regular than, the pattern in the 'basal surface'.

As to what is beneath this 'basal surface', it can be deduced from the electron micrographs of Fawcett (1966) and Pikó (1969) that it is the nucleus, and this has been confirmed for the rat spermatozoon by comparing the shape of the replicas with the shape of Feulgen-stained nuclei. From the work of Pikó, it seems that there is no matrix between the nuclear membrane and the cell membrane of the 'basal surface'. This is in contrast with the post-nuclear cap, which actually consists of a dense cytoplasmic lamina subjacent to the cell membrane (e.g. Fawcett \& Phillips, 1969, who consider the term post-nuclear cap a misnomer and suggest 'post-acrosomal dense lamina' instead). At present, the interpretation of the topography of the 'basal surface' is problematical. It may be that the absence of an intervening matrix in this region has resulted in the underlying chromatin becoming so severely desiccated before the deposition of carbon that its surface has developed a pattern of shrinkage cracks, to which the cell membrane has conformed. This interpretation is supported by the occasional appearance of reticular patterns in other parts of the surface of the nucleus after the cells have been sonicated. On the other hand, the topography of the 'basal surface' is possibly a manifestation of the lamellar body described by Pikó (1969) in the rat spermatozoon, a structure thought to be homologous with the evaginated or redundant nuclear membrane (of other species) first described by Nicander \& Bane (1962). This view is perhaps more consistent with the confinement of these features to the 'basal surface' and with the general orderliness of their arrangement.

The author gratefully acknowledges part-support from the Agricultural Research Council and the Ford Foundation.

\section{REFERENGES}

Fawcett, D. W. (1966) In: The Cell. Its organelles and inclusions, p. 21. Saunders, Philadelphia. Fawcett, D. W. \& Philirs, D. M. (1969) Observations on the release of spermatozoa and on changes in the head during passage through the epididymis. F. Reprod. Fert. Suppl. 6, 405.

\section{EXPLANATION OF PLATE 1}

The posterior region of the sperm head, with the 'posterior ring' arrowed. Negative prints of palladium-gold-shadowed carbon replicas. $\times 29,000$.

Fic. 1. Peromyscus polionotus. (The same region in $P$. maniculatus cannot be distinguished from that in $P$. polionotus.)

Fig. 2. Rattus norvegicus.

Frg. 3. Clethrionomys glareolus. 

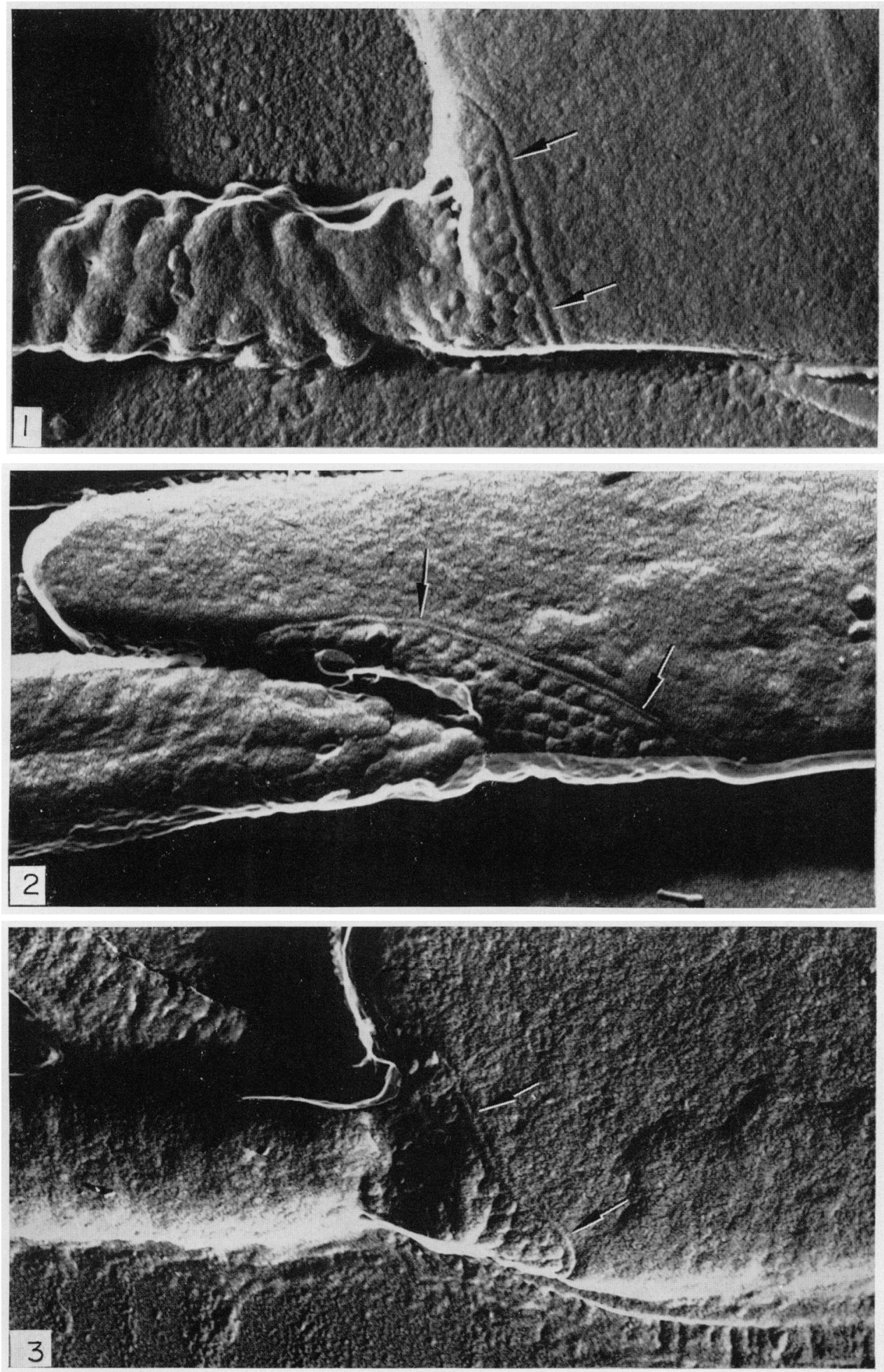

Fineing p. $36:$ 
Gresson, R. A. R. \& ZlotniK, I. (1945) A comparative study of the cytoplasmic components of the male germ-cells of certain mammals. Proc. $R$. Soc. Edinb. B, 62, 137.

Hancock, J. L. \& Trevan, D. J. (1957) The acrosome and post-nuclear cap of bull spermatozoa. Fl R. microsc. Soc. 76, 77.

NiCANDER, L. \& BANE, A. (1962) Fine structure of boar spermatozoa. Z. Zellforsch. mikrosk. Anat. 57, 390.

Prkó, L. (1969) Gamete structure and sperm entry in mammals. In: Fertilization, Vol. 2, Ch. 8, pp. 325-403. Eds. C. B. Metz and A. Monroy. Academic Press, New York.

Woolley, D. M. (1970) The midpiece of the mouse spermatozoon: its form and development as seen by surface replication. 7. Cell Sci. 6, 865 . 